\title{
Re-imagining Inclusive Education for Young Children: A Kaleidoscope of Bourdieuian Theorisation
}

\author{
Sunanta Klibthong ${ }^{1}$ \\ ${ }^{1}$ Monash University, Melbourne, Australia \\ Correspondence: Sunanta Klibthong, Monash University, Melbourne, Australia. E-mail: \\ sunanta.klibthong@monash.edu
}

Received: March 28, 2012 Accepted: April 5, 2012 Online Published: June 25, 2012

doi:10.5539/ies.v5n4p71 URL: http://dx.doi.org/10.5539/ies.v5n4p71

\begin{abstract}
This article discusses critical issues related to the development and practice of inclusive education of young children, from the perspective of Bourdieu's conceptual lenses of habitus, capital and field. The target question is: How can Bourdieu's lenses of critical social theory be applied to the development and implementation of early childhood inclusive education? Under this question, I situate early childhood inclusive education in four components (active learning environment, involvement, relationships and wellbeing), and critically analyse these in terms of Bourdieu's three conceptual lenses. I argue that effective inclusive education of young children must not conform to modernist epistemology, which locates knowledge exclusively in teachers and that, Bourdieuian conceptual tools offer refreshing epistemological and reflective radars for re-imagining and enacting pedagogical practices that contribute to all children's holistic development.
\end{abstract}

Keywords: inclusive education, modernist, bourdieu, early childhood

\section{Introduction}

Dissatisfaction with the classical education practices that construct children as simplistic and egocentric individuals (Piaget, 1929), and subsequently exclude children with additional needs/disabilities from equal participation in education has led to overwhelming support for inclusive education in many countries, including USA, New Zealand, Australia, UK and Canada. Classical education practices characterise children's mind as blank sheet on which educators can inscribe their knowledge. Also, classical education practices are in favour of placing children with disabilities in separate classrooms. This is opposed to a new sociology of childhood, which considers all children as capable individuals in their own right, who are curious and have rights and responsibilities to make significant contributions to society (Agbenyega, 2009; Fleer, 2011). Inclusive education is a philosophy that supports this notion, and is aimed at transforming schools to value individual children and meet their educational needs (Downing \& Peckingham-Hardin, 2007; Thousand, Villa, \& Nevin, 2002; Timmons, 2002).

The purpose of this paper is to discuss critical issues related to the development and practice of inclusive education of young children, from the perspective of Bourdieu's conceptual lenses of habitus, capital and field. The target question is: How can Bourdieu's lenses of critical social theory be applied to the development and implementation of early childhood inclusive education? Under this question, I situate early childhood inclusive education in four components (active learning environment, involvement, relationships and wellbeing), and critically analyse these in terms of Bourdieu's three conceptual lenses. The first part of the paper conceptualises inclusive education of young children. This is followed by a brief overview of the conceptual framework. Following this the conceptual framework is used to discuss the four components which I consider critical to successful inclusion. I conclude the paper by arguing that effective inclusive education of young children must not conform to modernist epistemology, which locates knowledge exclusively in teachers and that, Bourdieuian conceptual tools offer refreshing epistemological and reflective radars for re-imagining and enacting pedagogical practices that contribute to all children's holistic development.

\subsection{Conceptualising Inclusive Education for Young Children}

A plethora of research findings on inclusive education provide diverse conceptualisations of inclusion however, they all articulated a central call for early years education systems to enact social justice and equity in school 
management and pedagogical practices (Agbenyega \& Deku, 2011; Ashman, 2012; Barton, 2010; Loreman, Deppeler \& Harvey, 2010; UNESCO, 2009). The research literature on inclusion identified four main models of early childhood inclusion:

- Full inclusion: Typically developing children and children with additional needs participate fully in a program or service that caters for all children. This means inclusion focuses on the transformation of school cultures and pedagogy to increase access of all children, enhance the acceptance of all students, maximize children participation in various activity, and increase the achievement of and development of all children (Booth, Ainscow, Black-Hawkins, Vaughan, \& Shaw, 2000; Kalambouka, Farrell, Dyson, \& Kaplan, 2005).

- The cluster model: A group of children with additional needs participate together in a program that operates alongside a mainstream program

- Reverse inclusion: A few typically developing children participate in a program that caters largely for children with additional needs

- Social inclusion: Children with additional needs are catered for in special settings and come together with typically developing children at times for social experiences (Guralnick, 2001 cited in Kennedy, McLoughlin, Moore Gavidia-Payne, Forster, 2011, p. 39).

This paper focuses on the first model because, it demands from schools to transform their practices in order to meet the learning and developmental needs of all children. Some inclusive researchers define early childhood inclusion as "the values, policies, and practices that support the right of every infant and young child and his or her family, regardless of ability, to participate in a broad range of activities and contexts as full members of families, communities and society" (Allen \& Cowdery, 2012, p. 7). Therefore, early childhood inclusive education must accord all children the opportunity to co-construct knowledge with teachers rather than become assimilators of packaged knowledge (Agbenyega, 2011; Agbenyega \& Klibthong, 2011). It is recognised that cultural background, teachers' values and beliefs, and instructional practices direct what children learn and how they learn it (Ashman, 2012). Therefore, any attempt at developing and implementing inclusive early childhood education must consider and analyse contextual factors, including how teachers accept and value human difference, and the provision of necessary support for all children with and without disabilities to fully participate in the programmes of their choice (Allen \& Cowdery, 2012). At the core of early childhood inclusion are values, beliefs and institutional practices and how these are harnessed to work best for each individual child.

\section{How Can Bourdieu's Lenses of Critical Social Theory be Applied to the Development and Implementation of Early Childhood Inclusive Education?}

The critical social theory concepts (habitus, capital and field) developed by Bourdieu provide a kind of kaleidoscope for examining, critiquing and explaining the dynamic character of the processes at work in inclusive schools. I used Kaleidoscope as a metaphor here because it operates on the principle of multiple reflections, where several mirrors are attached together. In this sense, habitus, capital and field represent the reflective mirrors in the kaleidoscope which I have used in this paper to examine, critique and explain inclusive education development, and practices in their wholeness, origins and complexity. This method of critique originated in the area of critical theory and provides a kind of rewarding reflective study of the complexity of social systems of which inclusive schools form a part. Critical social theory epistemology is not a solution to a problem but methodological tool for analysing and critiquing educational systems, which are plagued with power, the status-quo and approaches that limit the enactment of equity, social justice and innovative practices (Bourdieu, 1998). By taking a critical position, inclusive activists and researchers can become aware of how theories of social justice and equity can help transform the social world and school practices (Bourdieu, 1998).

\subsection{Lens 1: Habitus}

Bourdieu conceptualises 'habitus' as "internalised embodied social structures” (Bourdieu, 1989, p. 18) and “cultural unconscious or mental habits or internalised master dispositions” (Bourdieu, 1989 cited in Houston, 2002, p. 157). This includes beliefs, values, norms and attitudes of individuals. Dispositions of teachers and children inevitably reflect the context in which they acquire them. Habitus influence the ways teachers relate with children and how they teach and involve them in activities. The mental structures and dispositions from which teachers make choices of the types of teaching approaches to use, and how they teach to include or exclude children from active participation in school work, are generated within the habitus. According to Bourdieu, habitus is embodied but visible through practice (Bourdieu, 1998). This means teachers' values, beliefs and dispositions become visible through how they conduct their practices in classrooms. Therefore, the only way to determine whether a teacher 
understands and values inclusion for social justice and equity, and takes children's contributions seriously, is through the creation of active learning environment, involvement, relationships and wellbeing.

For Bourdieu, habitus potentially induces a wide collection of possible actions, and at the same time, enables the individual to draw on transformative and constraining courses of action. He asserts that habitus:

is a kind of transforming machine that leads us to 'reproduce' the social conditions of our own production, but in a relatively unpredictable way, in such a way that one cannot move simply and mechanically from knowledge of the conditions of production to knowledge of the products (Bourdieu, 1993, p. 87).

Ritzer posits, "on the one hand, habitus is a structuring structure; that is, it is a structure that structures the social world. On the other hand, it is a structured structure; that is, it is a structure which is structured by the social world" (Ritzer, 1996, p. 541). To apply this understanding to inclusive practice means the composition of teachers' internalised master dispositions determine the ways they select teaching strategies and classroom management approaches. In doing teaching in a particular way, teachers produce practices to structure their students in a school which they are part of. That is, they can use their habitus to classify the members of their classrooms into various categories, for example, disabled, attention hyperactive disordered and so on. The teachers are in turn affected by their classificatory systems. For example, if teachers classify some children as limited in ability, they might do little to engage them. Children who have little engagement may in turn disrupt classroom teaching and learning.

\subsection{Lens 2: Capital}

Inclusive education of young children is influenced by capital, which can manifest in various forms - economic, cultural, social and symbolic. Economic capital - wealth defined in monetary terms can determine the choice and use of teaching resources in a particular teaching situation. Cultural capital refers to non-financial social assets such as educational or intellectual, which might promote social movement, for instance, interactions in class beyond economic means. Three subtypes of cultural capital can be identified as critical to inclusive education (embodied, objectified and institutionalized (Bourdieu, 1990). Embodied cultural capital consists of both the deliberately and passively acquired properties of one's self from the family through socialization of culture and traditions over time, and impresses itself on one's habitus. This becomes the character or way of thinking. An example of embodied cultural capital is linguistic capital, defined as "the mastery of and relation to language (Bourdieu, 1990, p. 114). This is so because it represents a means of communication and self-presentation acquired from one's surrounding culture, and is critical to teaching and learning in inclusive classrooms. Objectified cultural capital is made up of physical objects that are owned, such as works of art, which can be transmitted both for economic profit and for the purpose of symbolically conveying the cultural capital whose acquisition they facilitate. Institutional cultural capital consists of institutional recognition, credentials or qualifications, of the cultural capital held by an individual (Bourdieu, 1990). Recognized knowledge influences the nature of involvement, relationships and wellbeing in schools.

In inclusive education, social capital, which is capital constituted by social ties and symbolic capital, which is one's status, honour or prestige (Bourdieu, 1998) are critically important. These capitals govern the nature of relationships and situated wellbeing that exist in the inclusive classroom. They determine whether the classroom practices constitute oppressive practice or acts of social justice (Gorder, 1980).

Economic, symbolic, cultural and social capitals are critical elements in inclusive practice in many important ways. For instance, everyday relations between children and other children, and between teachers and children are influenced by them. Capital determines a teacher's and a child's agency - their ability to strategically engage in classroom activities and how they contribute to knowledge development (Webb, Schirato, \& Danaher, 2002). If teachers place less value on children's knowledge capital this may limit their capacity to be actively involved in own learning.

\subsection{Lens 3: Field}

Bourdieu's concept of 'field' denotes a spatial metaphor, a network of relations among objective positions. This conceptualisation is different from positivists' notion of 'field' as social location, for example, social milieu, context, and social background. Conceptualising field in a positivist sense is to disregard the sufficiently conflictual character of social lived experience (Mills \& Gale, 2007) which characterises inclusive education practice with young children. Field in the Bourdieuian sense, therefore, is a social arena in which people interact, maneuver and struggle in pursuit of desirable equity and social justice (Bourdieu, 1997). Therefore inclusive education practice is an arena in which there are constant struggles for the acquisition of knowledge, credentials and development. In inclusive classrooms both the teachers and children occupy distinct positions within the field 
in which struggles or manoeuvres take place over specific` knowledges or stakes, and access to them. The intellectual distinction between the teachers and children, values, prestige and social class in varying degrees define the stake of the teachers and the children. In this respect, contemporary inclusive school development with young children must adopt critical approach to interrogate and minimise the struggles between teachers' knowledge, their relationship with children, and the knowledge that children bring to their learning situations. A critical approach would enable teachers to embrace and enact genuine equity, value children and create opportunity for a more in-depth understanding of children's learning from an inclusive point of view (Deppeler, Moss \& Agbenyega, 2008).

\section{Focusing the Conceptual Lenses on Active Learning Environment, Involvement, Relationships and Wellbeing}

Active learning environment, involvement, relationships and wellbeing are key components of inclusive education of young children. Active learning environments support progressive and effective development of inclusive education because such learning environments are rich in play, focus on co-construction of meaning, curiosity and exploration. All children irrespective of their ability love to play (Fleer, 2011). Using play as a leading activity in learning enables both children with or without disabilities to engage in exploration and curiosity, and co-construct meaning (Fleer, 2011). This is opposed to modernist classrooms where the environment is less active, dominated by the teacher, and knowledge is passed on from the teacher to the child as a receptacle (Agbenyega \& Deku, 2011; Agbenyega, 2009; 2011).

Active learning environments promote involvement. Involvement is related to child initiated activities, persistence, complexity, creativity and play (Foreman, 2007; Odom, 2000). Inclusive education of young children require that they be involved in all aspect of their schooling (Booth, Ainscow, Black-Hawkins, Vaughan, \& Shaw, 2000; Kalambouka, Farrell, Dyson, \& Kaplan, 2005). Children who are involved persist on task and demonstrate complexity and creativity through play. In addition to involvement is relationship. This component relates to responsiveness, positive interactions, quality verbal exchanges and appropriateness in the learning environment. Above all, is the wellbeing of children within the learning environment, which focuses on children's happiness and satisfaction, social functioning, for example assertiveness and dispositions (Foreman, 2007). A learning environment cannot be described as inclusive when children are constantly frustrated, unhappy, terrified and confused. Wellbeing is therefore fundamental to relationship building and involvement in all activities, and for deep level learning (Pianta, 1999; van Kraayenoord, 2007).

The conceptual lenses of capital fields and habitus form an interactive complexity for examining and explaining the four interactive components of inclusive education. As it is pointed out, a "field can be any structure of social relations" (King, 2005, p. 223). It is a site of struggle for positions within that field and is constituted by the conflict created when individuals or groups endeavor to establish what comprises valuable and legitimate capital within that space (King, 2005). For example, in developing and enacting inclusive practice for young children, teachers and children with or without disabilities usually enter into relationship with differing capitals. Therefore, one type of cultural capital can be at the same time both legitimate and not, depending on what are valued in the field. The site of the field also determines the nature of relationship. It can be seen therefore, that the legitimation of a particular type of cultural capital is completely subjective. Therefore, the power to determine what constitutes legitimate cultural capital within a specific field is derived from symbolic capital. That is the honor or prestige accorded to the individual who possess this capital. This has great implication for children with disabilities in inclusive classrooms. Involvement of all children in learning activities, building positive relationship with them and ensuring their wellbeing are subject to teachers' habitus, capitals and the nature of the field.

Habitus is also important to the concept of inclusion and the four components of active learning environment, relationship, involvement and wellbeing. Cultural capital, capital can be derived from an individual's habitus. For instance, teachers' dispositions that are inculcated in them from their institutions of training and the family might manifest themselves in different ways in each individual and predispose them to a particular way of thinking and acting with implications for their practices (Harker, 1990; Gorder, 1980). It is argued that the habitus is formed "not only by the habitus of the family" (Harker et al., 1990, p. 11) but also by the "objective chances of the class to which the individual belongs" (King, 2005, p. 222), in "their daily interactions" (Gorder, 1980, p.226) and "it changes as the individual's position within a field changes” (Harker, 1990, p. 11). This means that teachers' social class might also influence the way they think about inclusion and the way they implement it. This also might influence the four components.

Importantly, the habitus, capital and field provide a theoretical space for critical mindfulness and reflexivity (Nagata, 2006) for analysing the essence of inclusive education in the light of active learning environment, 
involvement, relationships and wellbeing. Any epistemological and pedagogical strategy for developing and implementing solid inclusive education for young children needs to be created on the basis of principles of critical approach, which follows from the concepts of Bourdieu's theorisation. I consider this necessary because his concepts reflect different aspects of the complex process of inclusive education such as equity, social justice and human rights for young children. The essence of the critical approach is that it supports the deconstruction and reconstruction of the process of politics of difference in education (Apple, 1999; Robinson \& Diaz, 2008; Kincheloe \& Steinberg, 1997). This means the critical approach of studying and analysing inclusion makes the process of inclusion practice accessible for direct observation. In such approaches teachers might be able to capture practices as they happen naturally.

Critical approach to analysing inclusive development and practice could capture didactic and teacher directed learning or learning in an active environment where all children are involved. The critical approach, using Bourdieuian lenses, might also assist teachers or researchers in capturing children's happiness and satisfaction, social functioning for example, assertiveness whether these are compromised or supported. Research findings on inclusive education show that children demonstrate the lack of involvement by being frequently out of seat, fidgeting and throwing things at peers (Deppeler, Moss \& Agbenyega, 2008; Foreman, 2007). Other children show the lack of wellbeing through emotional outbursts and excessive crying (Ashman, 2012; Barton, 2010; Loreman, Deppeler \& Harvey, 2010). Some teachers in inclusive classroom might usurp their power over children through continuous outburst, compelling children to comply with existing classroom routines without any modification and adopting authoritative transmission approach in teaching young children. This can lead to less active learning environment with minimal child involvement. This can also limit children's capital formation, particularly those children with disabilities and significant learning needs. Activities rich in play, co-construction of meaning, curiosity, exploration recognise children's cultural capital. This might lead to a reduction in tension and struggles in the field (Bourdieu, 1990). When teaching remains classical and controlling it becomes counter-productive to inclusive education of young children (Freire, 2007).

On the one hand, when learning environments are inactive, and children are not involved the effect is that children engage in challenging behaviours and teachers may use most of their contact hours addressing behaviour problems. On the other hand, a new philosophy of teaching grounded in social justice and equity would help transform the teachers' pedagogy to organise group sessions and reduce the impact of large class sizes.

\section{Developing and Implementing Transformative Inclusive Education for Young Children}

To develop and implement inclusive education that caters to the needs of all young children with or without disabilities, teachers and children must co-construct educational spaces that are active, enact involvement, relationship and wellbeing (Agbenyega, 2011). This means early learning classrooms should no longer enact practices where teachers are positioned as the knowledge givers and the children as mere receptacles. Approaches to teaching are influenced by teachers' habitus (values, beliefs). In situations where children are perceived as simplistic participants, exclusion becomes the dominant practice. When children are regarded by teachers as non-experts they tend to impose predetermined structures on them which 'humiliate' their cultural capital knowledge and experiences. A positive image of children enables teachers to enact teaching practices that consider children's developmental strengths and their cultural and symbolic capital (Wacquant, 1998) which they bring to the inclusive classroom. Valuing children's knowledge adds richness to teaching and learning.

As explained in the beginning part of this paper inclusive education of young children is focused on educators' engagement with children, wellbeing, involvement and relationships (Bucholz \& Sheffler, 2009; Harrison, 2003; Mundia, 2009). This means teachers must not be the only ones that do talking in the classroom. Doing pedagogy in this way disconnects children from the real world. Involvement of children in learning leads to their emotional and intellectual wellbeing. Children's wellbeing is essential for their involvement and involvement is essential for deep level learning (Bucholz \& Sheffler, 2009; Mills \& Gale, 2007). For children to experience continuous wellbeing, they need to be in a positive network of relations with teachers and other children. This network is what Bourdieu refers to as field (Bourdieu 1998; Mills \& Gale, 2007). However, when classrooms reflect territories of wars between children and teachers (Bourdieu 1998), inclusive education moves further away from many disadvantaged children. Children's involvement increase through an active learning environment and an active learning environment strengthens relationships for inclusive education to be successful (Mundia, 2009). Therefore, the most important components to consider in inclusive practice are the power of the environment to support children's learning, indicators of involvement, relationships, wellbeing. These are interactive complex components and are necessary for a classroom to be called inclusive as they induce practices to support all children's learning priorities. 
I would like to point out that in the selection and use of teaching methods in inclusive classrooms with young children, teachers would always activate their skills taking from their habitus which they have acquired through culture and training (Bourdieu, 1989). The habitus of teachers, coupled with their various cognitive and cultural capitals, would dictate how they approach teaching and classroom management and sometimes, might constitute a situation like "fish in water," without feeling the weight of the water (Bourdieu, 1993). This means culture, and existing knowledge of teachers might kept them away from taking a critical view on their pedagogy with young children with diverse needs.

Teachers are social agents with habitus, inscribed in their bodies by past experiences and by virtue of their training (Houston, 2002). These past experiences and training may predispose them to think and teach in particular ways. But Habitus of the teachers can be transformed through training to generate appropriate and endlessly renewed pedagogical strategies that support inclusive education (Mills \& Gale, 2007). Inclusive education is complex practice that cannot be implemented with a single strategy. Teachers of young children therefore must be educated to cope with the dynamic, fluid and shifting inclusive practices that cannot restrict itself to pre-programmed and rigid set of activities but rather, approaches must be generative and transformative to respond to the complex needs of all children in schools (Tomasello, 2009).

Unless the development of inclusive schools consider the nature and extent of capitals and habitus that both the teacher and the children bring to classrooms, inclusive education can become a destabilising experience for many children. Bourdieu argues that schools are places of struggle and the outcome one receives is determined by the amount and nature of capital possessed by competing actors in that given field (Webb, Schirato, \& Danaher, 2002). Teachers' and children's position in the classroom are informed according to Bourdieu by hierarchy of the amount of knowledge and symbolic capital the individuals possess (Wacquant, 1998). Therefore, there is always an issue of social justice, human rights and equity when working with children in inclusive classrooms where unequal amounts of cultural capital, symbolic and knowledge capitals exist (Bourdieu, 1998).

Some teachers might perpetuate inequality and injustice against some children in their classes without knowing or desiring to do so (Bourdieu 1998; Mills \& Gale, 2007). To avoid this from happening teachers can use their well-designed instructions to create active learning environment, involve children, establish relationships and ensure all children's wellbeing by recognising different forms of capitals each child brings to the inclusive setting. This means recognising and authorising the contributions of their knowledge through their involvement and not treating them as mere listeners. This requires teachers to transform their internalised master dispositions (habitus) (Bourdieu \& Passeron, 1990). From this perspective the interrelationship between habitus and capital help in explaining how cultural and pedagogical knowledge affect the kinds of inclusive practice that teachers might developed and how they reproduce children's worlds (Webb, Schirato, \& Danaher, 2002).

I take another stand that inclusive education of young children must "take as one of its central projects an attempt to be discerning and attentive to those places and practices where social agency has been denied and produced" (Giroux, 2011, p. 3). My main message in this paper is that inclusive practice should not be viewed merely as sites for teachers to practice rhetoric, technique or routine approaches to teaching. It should be educational practices where teachers become activists in struggle to liberate children, particularly those with significant learning needs from disintegration into "cheerful robots" (Giroux, 2011, p. 3). Children would not benefit much from education, call it inclusive or not, if their teaching approaches continue to embrace classical and modernist epistemologies which position children as inferior and where matters of justice, human rights and power are not giving serious attention (Freire, 2007).

\section{Conclusion}

This theoretical paper attempts to claim a new and transformational space for developing and implementing inclusive education for young children. Using the conceptual lenses of habitus, capital and field (Bourdieu, 1990), attempt has been made to better understand the nature of active learning environment, involvement, relationships and wellbeing. I argue that the possibilities for inclusive education within these components could be compromised with teacher talk and didactic teaching because such teaching approaches still enact classical epistemology in which modernist notion of children as receptacles dominate (Kincheloe, 2008). Children cannot extend their knowledge in such learning environment and neither do such learning environments constitute inclusive settings. To advance the field of inclusive education, professional development that incorporates critical mindfulness and reflective practice (Nagata, 2006) for teachers should be paramount. Critical mindfulness helps teachers to move beyond their own habitus and capitals to interrogate their choices of pedagogical tools, their epistemological orientation, and the learning needs of every child. This means interaction between the teachers and children becomes the radar of inclusive practice. Reflexivity must also be an important component of teacher 
education for teachers. Reflexivity would keep teachers on course throughout their teaching processes. Bourdieu argues that reflexivity which is "an interrogation of the three types of limitations (social position, of field and of the scholastic point of view)... are constitutive of knowledge itself" (Schirato \& Webb, 2003, p. 539). This means applying reflexivity to their work the teachers would become conscious of their class, ethnicity, religion, and their situated position within the field in relation to the children they teach. In my personal view, the extent to which teachers can re-imagine and develop effective inclusive education for all children beyond rhetoric, is through conscious comprehension of reflexivity and critical mindfulness on Bourdieu's three conceptual lenses of habitus, capital and field (Bourdieu, 1990).

\section{References}

Agbenyega, J., \& Deku, P. (2011). Building new identities in teacher preparation for inclusive education in Ghana. Current Issues in Education, 14(1), 1-36.

Agbenyega, J. S. (2009). The Australian Early Development Index, who does it measure: Piaget or Vygotsky's child? Australasian Journal of Early Childhood, 34(2), 31-38.

Agbenyega, J. S. (2011). Institutional practices in early childhood teachers' construction and management of learning spaces: an encounter for inclusion or exclusion? International journal of Equity and Innovation in Early Childhood, 9(1), 62-76.

Agbenyega, J. S., \& Klibthong, S. (2011). Early Childhood Inclusion: a postcolonial analysis of pre-service teachers' professional development and pedagogy in Ghana. Contemporary Issues in Early Childhood, 12(4), 404-416.

Allen, E., \& Cowdery, G. E. (2012).The exceptional child: Inclusion in early childhood education. Belmont, CA: Wadsworth, Cengage Learning.

Apple, M.W.A. (1999). Power, Meaning and Identity: Essays in Critical Educational Studies. New York: Peter Lang.

Ashman, A. (2012). A culture of inclusion. In A. Ashman \& J. Elkins (Ed.). Education for inclusion and diversity (4th ed.) (pp. 1-33). French Forests, NSW: Pearson.

Barton, H. (2010). Strengthening the roots of planning. Planning Theory \& Practice, 11(1), 95-101.

Booth, T., Ainscow, M., Black-Hawkins, K., Vaughn, M., \& Shaw, L. (2000). Index for inclusion: Developing learning and participation in schools. Bristol, England: Centre for Studies on Inclusive Education.

Bourdieu, P., \& Passeron, J. C. (1990). Reproduction in education, society and culture (2nd ed.), London, Sage.

Bourdieu, P. (1989). Social Space and Symbolic Power. Sociological Theory, 7, 14-25. http://dx.doi.org/10.2307/202060

Bourdieu, P. (1990). In other words: Essays towards a reflexive sociology. Stanford, Stanford University Press.

Bourdieu, P. (1993). Sociology in question. London: Sage.

Bourdieu, P. (1997). The forms of capital. In A. Halsey \& H. Lauder \& P. Brown \& A. S. Wells (Eds.) Education: Culture, economy and society (pp. 46-58). Oxford: Oxford University Press.

Bourdieu, P. (1998). Practical reason: On the theory of action. Cambridge: Polity.

Bucholz, J. L., \& Sheffler, J. L. (2009). Creating a warm and inclusive classroom environment: Planning for all children to feel welcome. http://www.cehs.wright.edu/ prenick/Spring_Summer09_Edition/htm/bucholz.htm

Deppeler, J., Moss, J., \& Agbenyega, J. S. (2008). The ethical dilemma of working the visual and digital across space. In J. Moss (Eds.), Researching education visually, digitally and spatially (pp. 209-227). Amsterdam: Sense Publications.

Downing, J., E., \& Peckingham-Hardin, K. D. (2007). Inclusive education: What makes it a good education for students with moderate to severe disabilities? Research \& Practice for Persons with Severe Disabilities, 32(1), 16-30.

Fleer, M. (2011). Conceptual play: foregrounding imagination and cognition during concept formation in early years education. Contemporary Issues in Early Childhood, 12(3), 224-237. http://dx.doi.org/10.2304/ciec.2011.12.3.224

Foreman, P. (2007). Inclusion in action. Victoria: Thomson. 
Freire, P. (2007). Pedagogy of the Oppressed. New York: Continuum International Publishing Group.

Giroux, H. A (2011). On critical pedagogy. New York: The Continuum International Publishing group.

Gorder, K. (1980). Understanding School Knowledge: a critical appraisal of Basil Bernstein and Pierre Bourdieu. Sage Publications: London.

Harker, R. (1990). Education and Cultural Capital. In Harker, R., Mahar, C., \& Wilkes, C., (eds). An Introduction to the Work of Pierre Bourdieu: the practice of theory, Macmillan Press, London.

Harrison, S. (2003). Creating a successful learning environment for postsecondary students with learning disabilities: policy and practice. Journal of college Reading and Learning, 33(2), 131-145.

Houston, S. (2002). Reflecting on Habitus, Field and Capital: Towards a Culturally Sensitive Social Work. Journal of Social Work, 2(2), 149-167. http://dx.doi.org/10.1177/146801730200200203

Kalambouka, A., Farrell, P., Dyson, A., \& Kaplan, I. (2005). The impact of population inclusivity in schools on student outcomes. In Research Evidence in Education Library. London: EPPI-Centre, Social Science Research Unit, Institute of Education, University of London.

Kennedy, A., McLoughlin, J., Moore, T., Gavidia-Payne, S., \& Forster, J. (2011). Early childhood intervention project: A revised literature review. Melbourne: DEECD.

Kincheloe, J., \& Steinberg, S. R. (1997). Changing Multiculturalism. Buckingham: Open University Press.

King, A., (2005). Structure and Agency. In Harrington, A., (eds). Modern Social Theory: an introduction (pp. 215-232). Oxford University Press, Oxford.

Loreman, T., Deppeler, J., \& Harvey, D. (2010). Inclusive education: supporting diversity in the classroom. New York, NY: Routledge.

Mills, C., \& Gale, T. (2007). Researching social inequalities in education: towards a Bourdieunian methodology. International Journal of Qualitative Studies in Education, 20(4), 433-447. http://dx.doi.org/10.1080/09518390601176523

Mundia, L. (2009). Implementation of inclusive education in Brunei Darussalam: Review of possible implication for school counselors. Retrieved from http://www.cehs.wright.edu/ prenick/Spring_Summer09_Edition/htm/mundia.htm

Nagata, A.L. (2006). Cultivating researcher self-reflexivity using voice and mindful inquiry in intercultural education. Journal of Intercultural Communication, 9, 135-154.

Odom, S. L. (2000). Preschool inclusion: What we know and where we go from here. Topics in Early childhood Special Education, 20(1), 20-27. http://dx.doi.org/10.1177/027112140002000104

Piaget, J. (1929). The child's Conception of the World. New York: Harcourt Brace.

Pianta R. C. (1999). Enhancing relationships between children and teachers. Washington DC: American Psychological Association. http://dx.doi.org/10.1037/10314-000

Ritzer, G. (1996). The McDonaldization of Society. Thousand Oaks, CA: Pine Forge Press.

Robinson, K. H., \& Diaz, C. J. (2008). Diversity and Difference in Early Childhood Education: Issues for theory and practice. New York: Open University Press.

Schirato, T., \& Webb, J. (2003). Bourdieu's concept of reflexivity as metaliteracy. Cultural Studies, 17(3-4), 539-553. http://dx.doi.org/10.1080/0950238032000083935

Thousand, J. S., Villa, R. A., \& Nevin, A. I. (2002). Creativity and collaborative learning: The practical guide to empowering students, teachers, and families ( $2^{\text {nd }}$ ed.). Baltimore, MD: Paul H. Brookes.

Timmons, V. (2002). International perspectives on inclusion: Concluding thoughts. Exceptionality Education Canada, 12(2), 187-192.

Tomasello, M. (2009). Culture and cognitive development. In L. S. Liben (Ed.). Current directions in developmental psychology (pp.207-212). Boston, MA: Pearson.

UNESCO. (2009). Policy guidelines on inclusion in education. Paris, UNESCO.

Van Kraayenoord, C. E. (2007). School and classroom practices in inclusive education in Australia. Childhood Education, 83(6), 390-394. 
Wacquant, L. (1998). The Double-Edged Sword of Reason: The Scholar's Predicament and the Sociologist's Mission. European Journal of Social Theory, 2(3), 275-281. http://dx.doi.org/10.1177/13684319922224491

Webb, J., Schirato, T., \& Danaher, G. (2002). Understanding Bourdieu, Sage Publications: London. 